|EURE Vol $39 \mid$ N $^{\circ} \mathbf{1 1 8} \mid$ Septiembre $2013 \mid$ pp. 173-198 | artículos | OEURE

\title{
Indicadores de tercera generación para cuantificar la sustentabilidad urbana. ¿Avances o estancamiento?
}

Silvia León A. Universidad Piloto de Colombia, Bogotá, Colombia

RESUMEN | Las intrincadas relaciones que caracterizan el metabolismo de las zonas urbanas precisan ser visualizadas mediante fórmulas simplificadas, capaces de respaldar la toma de decisiones en favor de la sustentabilidad urbana. En el marco teórico ordenador de la Coevolución (Norgaard, 1984), y el cálculo del Análisis de Flujo de Materiales (AFM) y de la Huella Ecológica Local (HEL) para la Región Metropolitana de Santiago (Chile) y la ciudad-región de Bogotá (Colombia), se muestra dicha dupla (AFM y HEL) como indicadores de tercera generación - vinculantes, locales, sinérgicos y transversales - que incorporan simultáneamente diversas variables con amplias categorías y dimensiones, además de un alto grado de aporte (el $80 \%$ ) a la cuantificación de la sustentabilidad urbana. El posicionamiento de lo local, por medio de la huella ecológica local, también prevalece en el mejoramiento de los indicadores relativos a la sustentabilidad de una urbe específica, por encima de la estandarización de las metodologías basadas en comparaciones o rankings internacionales.

PALABRAS CLAVE | sustentabilidad urbana, gestión urbana.

ABSTRACT | The intricate relationships that characterize the metabolism of urban areas need to be viewed through simplified formulas, so that they can support the decision-making processes leading to urban sustainability. In the framework of the Co-evolution paradigm (Norgaard, 1984) and the calculation of Material Flow Analysis and the Local Ecological Footprint regarding the Metropolitan Region of Santiago (Chile) and the city-region of Bogotá (Colombia), Material Flow Analysis and the Local Ecological Footprint are shown as third-generation indicators - binding, local, synergic and cross-cutting - simultaneously incorporating several variables with broad categories and dimensions, and a high degree of contribution (80\%) to the quantification of urban sustainability. The positioning of the local, through the local ecological footprint, also prevails in the improvement of indicators relative to the sustainability of a specific urban area, beyond the standardization of methodologies based on international comparisons or rankings.

KEY WORDS | urban sustainability, urban management.

Recibido el 25 de noviembre de 2011, aprobado el 1 de diciembre de 2012

E-mail: silvia-leon@unipiloto.edu.co 


\section{Introducción}

Los actuales asentamientos humanos latinoamericanos, "manchas en constante crecimiento" por la dinámica poblacional expresada en growth sprawl, con ciudadanos de diferentes clases sociales, provocan un constante aumento en los consumos de energía, agua, alimentos, recursos naturales, y cada vez mayores requerimientos de fuentes fósiles para su movilidad, productividad y diario vivir (o para sobrevivir, la mayoría de ellos). A esto se suma un incremento permanente de las emisiones y los vertimientos, los que, sin lugar a dudas, exacerban los impactos sobre los ecosistemas que les subyacen, pese a los colosales intentos actuales a escala mundial, nacional y local por la minimización de tales externalidades negativas. Y por corresponder a un ciclo natural intrínseco que caracteriza la mutua relación entre sociosistemas y ecosistemas, dichas externalidades surgen desde las urbes y regresan hacia las mismas urbes, pasando por los ecosistemas.

Probablemente mediante el concepto de coevolución de Norgaard (1984) se expliquen las "mutaciones", las alteraciones y las transformaciones que sufren los ecosistemas -hasta sobrepasar, en algunos casos, su capacidad de resiliencia-, suscitadas por las actividades antrópicas (realizadas por cada sociosistema de una ciudad-región determinada) destinadas a obtener los recursos necesarios y atender a sus propias necesidades. Este enfoque coevolucionista tiene plena coherencia con los actuales modelos de urbanización, los cuales demuestran una imperativa dependencia de las urbes respecto de los flujos externos - provenientes de los ecosistemas (llámense también naturaleza o medioambiente)-, con una clara diferencia en el tiempo: la total dependencia de las urbes frente al entorno y la independencia absoluta de los ecosistemas en ausencia del hombre.

No obstante, nuestras ciudades, aquellas que se esparcen indefinidamente sobre un terreno que parece no tener límites (Ducci, 1998), provocan otro efecto que hoy se detecta en forma inmediata a raíz de la dispersión, el cual corresponde a la dificultad de establecer un límite nítido entre lo urbano y lo rural, entre lo urbano y lo natural (zonas de conservación o protección). Tal límite es requerido en las políticas públicas positivistas para la delimitación político-administrativa de una ciudad, que se hace con imprecisión cuando no hay una distinción clara entre lo urbano y lo rural. A ello se agrega que los ecotonos, definidos como esas hectáreas de transición entre lo urbano y lo natural y donde también es preciso respetar la identidad de lo rural inmerso entre ambos, poseen características peculiares que complejizan aún más el núcleo problemático de los estudios urbanos.

Es claro, así, que en los procesos de crecimiento urbano impera la complejidad; que no son tan claras y exactas las variables intervinientes, y tampoco son precisas ni están plenamente establecidas las relaciones, las causas y los efectos. En consecuencia, es fundamental buscar en la simplicidad una herramienta metodológica cuantitativa para evaluar la coevolución entre los sociosistemas y los ecosistemas, incluyendo los ecotonos. Después de esto, ajustar los modelos de desarrollo urbano cuyas directrices son las políticas urbanas, para introducirlos 
nuevamente en la interacción de los sistemas social y ecológico. De esta manera se dará lugar una vez más a la complejidad, para reiniciar un ciclo en el cual el "deber ser" es la maximización de las externalidades positivas y la mitigación de las externalidades negativas ocurridas en la ciudad-región, demostradas mediante métodos holísticos susceptibles de interpretación por parte de cualquier stakeholder urbano.

El actual paradigma de la sustentabilidad urbana, permeado en doble vía desde la sociedad civil hacia la clase política y viceversa, intenta promover una "r-evolución", para no concebir la ciudad como un universo aislado, sino identificar la real interacción de los conglomerados urbanos con los ecosistemas, reconociendo su inherente complejidad. La confluencia de los actores del sociosistema (público, privado y sociedad civil) frente al manejo de los ecosistemas (que sostienen y sustentan las ciudades) en pro de mejorar la calidad de vida urbana, exige el diseño de metodologías lógicas y coherentes de cuantificación de la sustentabilidad urbana. Deben ser metodologías constituidas por indicadores de tercera generación, de tal manera que lo sustentable sea más palpable en términos positivistas, y que permitan corroborar que las políticas públicas (toma de decisiones) efectiva y eficazmente están conduciendo el desarrollo urbano hacia dicho propósito.

Hoy tenemos que el desarrollo sostenible ha sido relativamente dinámico en crear orientaciones estratégicas hacia una planificación más integral -planificación estratégica-; sin embargo, solo en los últimos años se han priorizado las metodologías y los indicadores para la evaluación de las intervenciones relacionadas con dichas planificaciones (Barton, Jordán, León \& Solís, 2007). Probablemente los indicadores disponibles y aplicados hasta el momento en diferentes lugares del mundo proporcionan información parcial mediante el uso de indicadores de primera y segunda generación, ${ }^{1}$ los que ofrecen conclusiones sectoriales, estáticas, sesgadas por su mirada parcial y con ausencia de transversalidad, e impiden así conocer de manera holística la sustentabilidad de las ciudades-región; es decir, develar la coevolución de los ecosistemas que sustentan los sociosistemas.

Los conceptos "desarrollo sostenible" y "sustentabilidad urbana", presentes en los paradigmas aplicables por los investigadores urbanos, son considerados como sinónimos diferenciados solo por el manejo teórico, de tal manera que el primero hace referencia a la escala de pais (lo nacional, incluso lo global) y el segundo a la escala de ciudad o ciudad-región. Se cumple así una armonía de sintaxis, género y número, entre "país" y "desarrollo sostenible", y entre "ciudad" y "sustentabilidad urbana" (León, 2009).

La sustentabilidad urbana se especifica como un fenómeno complejo de largo plazo, con dinámica propia, que busca mejorar la calidad de vida de la población urbana. Su operacionalización se define en forma participativa y negociada entre

$1 \longdiv { \text { Son de primera generación los indicadores relacionados con variables físicas, químicas y biológicas, que bien pueden } }$ correlacionarse con los denominados indicadores sectoriales o ambientales clásicos. De segunda generación son aquellos compuestos por cuatro grupos de variables: económicas, sociales, ambientales e institucionales, pero sin integración transversal y sin una táctica holística (Franchini \& Dal, 2000). 
las instituciones gubernamentales, la sociedad civil y los privados, con asistencia de la academia, con una visión intra e intergeneracional, y con un reconocimiento de lo local y lo regional por encima de lo nacional y lo internacional (León, 2006). Su cuantificación precisa de indicadores y no solo parámetros, por lo que se intenta avanzar en ese procedimiento mediante instrumentos conocidos como indicadores de primera y segunda generación, pues los de tercera generación ${ }^{2}$ están aún sin construir (Gross \& Arrué, 2005), aunque con la presente investigación se podrá afirmar que ya están en proceso de construcción. Este punto permite enfatizar la relevancia que tiene la conceptualización de la sustentabilidad para cada ciudad en particular, y así definir en esa misma dirección los indicadores que medirán "la brecha existente entre el desarrollo actual y aquel definido como sostenible" (Opschoor \& Reijnders, en Castro, 2002, p. 207). Es decir, se pretende reflejar el estado cuantitativo o cualitativo de un determinado fenómeno o proceso que se evalúa -en este caso, la sustentabilidad urbana-, aspecto de enorme importancia para hacer juicios sobre las condiciones del sistema actual, pasado (Quiroga, 2001) o futuro de una urbe.

\section{¿Avances o estancamiento respecto de los indicadores de tercera generación?}

A nivel mundial, la promulgación de indicadores se remonta a épocas antiguas, y siempre han sido considerados una herramienta positivista para hacer seguimiento a un fenómeno en el tiempo. Han sido una técnica corrientemente utilizada, aunque cronológicamente diferenciable. Según Castro (2002), en la década de 1930 los indicadores se usaban para la evaluación de determinados contextos económicos, por ejemplo el PIB y la curva Kuznets; en la década de 1960, para el ámbito social; y en la década de 1970, para el medio ambiente.

Más recientemente fueron introducidos los diagramas de modelos conceptuales, que se consolidaron con el establecimiento del sistema de indicadores. Entre ellos, vale destacar el Sistema de Familias, IRDS (Sistema de Indicadores Regionalizados de Desarrollo Sostenible) de Chile (1998), en el que aparece una mayor integración de las dimensiones de la sustentabilidad y se agrupan los aspectos ecológico, ambiental, social, económico e institucional; no obstante, su desventaja es el condicionante de un enfoque sectorial. Otro sistema revelador es el propuesto en el proyecto de ESALC (Evaluación de la Sostenibilidad en América Latina y el Caribe), en el que se expresa una interpretación sistémica de la realidad, entendida como un conjunto socioecológico que se divide a su vez en cuatro subsistemas; su desventaja radica, según Larrea, Martínez, Quiroga y Román (2007), en la complejidad del diagrama para el público no experto.

Los marcos ordenadores del PER (Presión Estado Respuesta) propuesto por la Organización para la Cooperación y el Desarrollo Económicos (OCDE), el PEIR (Presión Estado Impacto Respuesta), adoptado por la Organización de las

2 Son de tercera generación aquellos indicadores exclusivos al quehacer de la sustentabilidad, vinculantes, sinérgicos o transversales, que incorporen simultáneamente varios atributos o dimensiones de la ciudad (Gross \& Arrué, 2005). 
Naciones Unidas (ONU), y su modificación PEI/ER (Presión Estado Impacto/ Efecto Respuesta) del Centro Internacional de Agricultura Tropical (CIAT) de Colombia, tienen la ventaja de una integración sólida de las relaciones entre los sistemas social y ecológico. No obstante, poseen desventajas muy similares a los anteriores; es decir, tienden a promover políticas remediales cortoplacistas, son limitantes fuera de la dimensión ambiental, provocan una tendencia de linealidad y causalidad que no da cabida a la transversalidad, y no dan cuenta de las interrelaciones complejas entre los sistemas (Quiroga, 2001), las que son fundamentos requeridos para hablar de sustentabilidad urbana.

Los modelos o marcos ordenadores propuestos por la Unesco (Organización de las Naciones Unidas para la Educación, la Ciencia y la Cultura), además de revelar la compleja noción del concepto "sustentabilidad" de una manera sintetizada, validan la formulación de diversas perspectivas. Sus diagramas tienen la ventaja de resaltar la intersección entre distintos conjuntos que dan cuenta de la existencia de traslapes entre las áreas temáticas, aunque la división en conjuntos no deja de ser una operación sectorializadora de una realidad que, de hecho, es mucho más sistémica e interrelacionada. Según Larrea et al. (2007), el uso de formas, colores y términos simples en los diagramas muestra la evolución conceptual con una gran fortaleza: la comunicacional, pues permite expresar de modo contundente y sencillo las distintas dimensiones de la sustentabilidad con una clara vocación englobadora.

Una vez establecido el modelo conceptual y su correspondiente diagrama, respaldados por plataformas fundadas en la innovación, por potentes marcos teóricos, por una definición clara del episteme, por la crítica de los modelos y los diagramas existentes, y validados dentro del concepto de sustentabilidad urbana asumido por la investigación, cobra relevancia el establecimiento del sistema de indicadores de tercera generación. Esta última búsqueda de indicadores vinculantes, sinérgicos o transversales ha generado propuestas como: IBES (Índice de Bienestar Económico Sostenible); IPG (Índice de Progreso Genuino); AFM (Análisis de Flujo de Materiales); Huella Ecológica; Mochila Ecológica; Índice de un Planeta Vivo; Factores en Ecoeficiencia, Factor 4, Factor 10; MIPS ( $\mathrm{Ma}$ terial Input Per Unit of Service/Insumo Material por Unidad de Servicio), TMR (Total Material Requirement/Requerimiento de Masa Total), TEV (Total Economic Value/Valor Económico Total), entre otros.

Los indicadores mencionados en el párrafo anterior corresponden a enfoques conmensuralistas, ${ }^{3}$ con obvias ventajas y desventajas frente al denominado enfoque sistémico. ${ }^{4}$ La apreciación personal, y bajo el episteme positivista de la investigación, llevó a optar por el enfoque conmensuralista, pues se consideran

Conmensurable: sujeto a medida; relacionado a cantidades cuya razón es un número racional.

4 Es importante no confundir el significado del término "sistémico" en el contexto de los indicadores, con la noción "sistémico" del marco teórico de la sustentabilidad (social y ecológico). Aquí el enfoque sistémico se refiere al que renuncia a los "megaindicadores" y al intento agregatorio, y se inclina por un conjunto de indicadores que muestran tendencias vinculantes y sinérgicas dentro del metabolismo complejo de un territorio. Según Quiroga (2001) comprende indicadores ambientales (biofísicos) e indicadores de desarrollo sostenible (biofísicos y socioeconómicos). 
más relevantes las ventajas de lo conmensurable, debido a su capacidad de síntesis y la revelación inmediata de los fenómenos. Estos indicadores se construyen agregando diversas variables que se asumen como componentes de un fenómeno, $\mathrm{y}$ a las cuales se les asigna un peso relativo respecto del resto a la hora de sumar todos los efectos. Además, se coincide con Quiroga (2001) al afirmar que el enfoque conmensuralista se acerca a la transversalidad y se aleja del análisis sectorial.

La diversidad de indicadores pertenecientes a lo conmensurable es una evidencia de la evolución que se ha dado en ellos, una evolución que tiene un objetivo básico y de desafío: mejorar los procedimientos de cuantificación de la sustentabilidad urbana. De esta manera se llega a la aplicación de la primera fase de la herramienta metodológica diseñada para la evaluación de la sustentabilidad urbana, a partir del Análisis de Flujo de Materiales (AFM) y la Huella Ecológica Local (HEL), cuyos objetos de investigación fueron la Región Metropolitana de Santiago (Chile) en 2006 y la ciudad-región de Bogotá (Colombia) en 2010.

En este orden de ideas, el objetivo general de la investigación fue establecer el grado de aporte de la dupla Análisis de Flujo de Materiales y Huella Ecológica Local, como indicadores de tercera generación, en la cuantificación de la sustentabilidad urbana en dos ciudades latinoamericanas.

La evaluación cuantitativa de las relaciones entre los sociosistemas y los ecosistemas presentes en ambas ciudades latinoamericanas acoge el Análisis de Flujo de Materiales cuya conceptualización original fue definida por Hinterberger, Giljum y Hammer (2003) y que se mantiene hasta hoy como un método útil para la cuantificación de los flujos de materiales intercambiados entre un sistema social y su entorno ecológico. No obstante, para el proceso de cálculo es básico incorporar las innovaciones realizadas en los casos del Greater London (Chartered Institution of Wastes Management [IWM], 2002) y la Región Metropolitana de Santiago (León, 2006). Respecto de la Huella Ecológica, se retoman las bases teóricas del método propuesto en 1996 por Mathis Wackernagel y William Rees (2001), aplicado ampliamente en todo el mundo y actualizado en 2006, con una notable diferencia de innovación: el cálculo de la Huella Ecológica Local (HEL, adición del adjetivo "local") por las consideraciones descritas más adelante.

Un aspecto fundamental es el desafío de superar las críticas a ambos indicadores, que han sido múltiples y variadas; no obstante, se diferencian las que efectivamente se comparten con otros autores y las que se objetan por no corresponder a una evidencia dentro de la investigación, al haber sido subsanadas mediante la incorporación de una estrategia específica.

En este orden de ideas, la justificación de la investigación se apoya en tres hechos: i) su carácter global, ii) su índole local, y iii) su aporte al conocimiento.

El primer hecho se inscribe en la actual tendencia mundial a centrar la atención en las ciudades, para lo cual el paradigma vigente eleva a absoluta necesidad el mejoramiento de la calidad de vida de los ciudadanos, posicionado dicho principio por las políticas urbanas, pero mediante la homogenización que 
impone la globalización. En este sentido, la globalización debe ser manejada con precaución en lo que respecta a la homogeneización, pues ello riñe con los postulados de la sustentabilidad urbana. Se debe mantener por encima de toda vanguardia economicista la identidad de cada asentamiento humano, las particularidades que lo hacen diferente, las costumbres propias de su gente y el individualismo de cada urbe. El valor de lo local. Bajo ninguna argumentación científica o política puede ser homogeneizado el significado de la calidad de vida para todas y cada una de las ciudades del mundo. El derecho a la identidad, a la diferencia y a la diversidad no es negociable. Significa ello que la replicabilidad de las experiencias exitosas debe hacerse con responsabilidad, para adaptarlas a las condiciones propias del nuevo asentamiento humano en el cual se pretenden implementar, de modo que no causen mayor caos del que pudiera existir localmente.

El segundo hecho, lo local, está interconectado plenamente con el primero, lo global, y tuvo una óptica más positivista en la justificación de la investigación, pero igualmente relevante. Se refiere a la compilación de la contabilidad de los recursos naturales y los materiales utilizados tanto por los ciudadanos de Santiago (Chile) como por los habitantes de Bogotá, determinando los flujos de materiales, las áreas dispuestas como sumideros en ambas capitales; también apunta a establecer qué tan sustentable es el ritmo de vida de estos dos sociosistemas capitalinos respecto de los ecosistemas sobre los cuales se expanden y se sustentan. ¿Cuál es el metabolismo del área metropolitana/de la ciudad-región? ¿Cuánto se utiliza? ¿Cuántas toneladas de alimentos, materiales de construcción, papel, electrodomésticos, metales, entre otros, se producen, exportan, importan y consumen? Asimismo, ¿cuántos millones de litros de agua se consumen?, ¿cuántos millones de toneladas de $\mathrm{CO}_{2}$ se producen por el transporte de los residentes capitalinos, ¿cuántos GW de energía utilizan los sectores residencial, industrial, comercial, agrícola?, y ¿cuántas hectáreas de suelo agrícola se destinan a otros usos? Los resultados obtenidos se convierten en la base fundamental para las políticas públicas que orientan el desarrollo de ambas ciudades latinas.

El tercer hecho, aportes al conocimiento, comprende la utilización de nuevos procedimientos en la aplicación de los métodos de cálculo del Análisis de Flujo de Materiales y la Huella Ecológica a partir del reconocimiento de las críticas a ambos indicadores, para superarlas total o parcialmente. ${ }^{5}$ Con dicho alcance se llegó a proponer una modificación a la Huella Ecológica y a formular la Huella Ecológica Local (HEL), cuya principal diferencia con la original de Wackernagel y Rees (2001) radica en el establecimiento de factores de productividad o rendimiento locales, es decir, factores particulares para Bogotá y también para Santiago de Chile, y en no utilizar factores de productividad/rendimiento globales.

5 No fue posible superar las críticas respecto de los daños acumulativos en los ecosistemas, descritos por Wiedmann (2005) y Yue et al. (2005), y solo parcialmente se pudo precisar las diferencias de impactos o consumos por grupos socioeconómicos (Agudelo, 2002). 


\section{Resultados}

Los resultados que se describen a continuación de manera detallada corresponden a la ciudad-región de Bogotá, ya que las conclusiones específicas de la Región Metropolitana de Santiago están publicadas en Barton, Jordan, León y Solís (2007); sin embargo, en el Anexo 1 se presenta el cuadro comparativo del metabolismo de ambas ciudades latinas, y están desagregadas las variables utilizadas y sus correspondientes categorías. Tal tentativa es posible debido a que en ambos marcos teóricos se optó por una postura sistémica (ecosistema y sociosistema), enmarcada por el planteamiento coevolucionista de Norgaard (1984), y tendiente a aplicar la argumentación de Turner (1992) en relación con la imperiosa necesidad de conservar el stock del capital natural crítico.

Las conclusiones obtenidas muestran que el proceso evolutivo de la ciudad-región de Bogotá en el tiempo la ha llevado desde ser un pueblo con zonas adyacentes, a ser un municipio con territorios colindantes, para terminar hoy como una ciudad con regiones circundantes; ello implica que el radio de expansión de la ciudad-región hace su diámetro cada vez más distante del punto original de fundación. Han aumentado también las proyecciones en torno a las redes de cooperación, para lo cual han sido paso obligado la transformación de su institucionalidad y nuevos discursos políticos, reflejados tanto en los planes de desarrollo distrital como en los de ordenamiento territorial, donde se plantea la gestión urbana bajo la óptica de ciudad-región. Este soporte político-institucional incluye las veinte localidades que conforman el Distrito Capital de Bogotá.

La ciudad-región se considera un sistema abierto y tiene cada vez mayores consumos, sin tornarse en excesivos, conclusión establecida a partir de las tendencias presentadas por las variables agua, alimentos, energía, materiales, residuos, transporte, usos del suelo y población durante los períodos 1997-1998 y 2007-2008; muy probablemente este comportamiento "mesurado" en algunos de los consumos tiene relación, entre otros factores, con la crisis asiática, cuyas repercusiones en Bogotá se dieron por el fenómeno de contagio de las crisis mundiales a partir de 1998. Algunos ejemplos que ilustran los casos de mayores aumentos en los consumos son: i) el de energía eléctrica por parte del sector industrial en 1997-1998, que alcanzó a 1.248 GWh, mientras que en el año 2007-2008 fue de 1.702 GWh (Departamento Administrativo Nacional de Estadísticas [DANE], 2009), vale decir, un aumento del 36,3\%; ii) el consumo de ganado porcino, que creció de 19.301 toneladas en 1997-1998 a 32.393 toneladas en 2007-2008, un alza del 67,8\%; iii) el parque automotor de microbuses y colectivos en $1997-1998$ era de 3.797 y pasó a 5.238 en el año 2007-2008, es decir, un incremento del 38\%; iv) el número de motocicletas nuevas en el período $1994-2000$ fue de 4.308 y en el período $2004-2007$ fue de $74.106 ;{ }^{6} \mathrm{v}$ ) por último, un comportamiento preocupante para la sustentabilidad de la ciudad-

6 El número total de motocicletas en 1993 era de 24.365 y en el año 2007 aumentaron a 103.742 (Cámara de Comercio de Bogotá, 2009). 
región se identificó en el parque automotor privado, el que pasó de 220.403 en 1995 a 895.293 en 2008.

A partir del cálculo del AFM se obtuvieron los siguientes resultados para las variables analizadas en los dos períodos (1997-1998 y 2007-2008), que comprenden principalmente uso del suelo, y consumo de agua, alimentos, energía; residuos, transporte, además de otras menos profundizadas en la investigación, relativas a materiales.

En relación con la variable Uso del suelo, se establecieron para la ciudad-región tres eventos repetitivos y ejemplarizantes en su modo de expansión, los cuales se han dado con mayor dinamismo desde hace siete décadas, debido al auge de Bogotá como principal "destino para los desplazados" y el eslogan "ciudad de oportunidades", donde el suelo urbanizable se "reproduce en laboratorio" a partir de los humedales, los cerros y las tierras agrícolas. El primer evento se da por la reducción -año tras año- del área de cada uno de los ecosistemas naturales, de cada humedal, mediante los rellenos antrópicos, la desecación del lecho, el deterioro de la calidad del agua que ayuda al proceso de colmatación del humedal, la construcción de zonas duras y canales, la prolongación del proceso de urbanización hasta su borde, y la posterior intervención de las autoridades para legalizar el nuevo conglomerado urbano (Corporación Autónoma Regional de Cundinamarca, 2000). El segundo y tercer eventos permiten la obtención de suelo urbanizable a partir de los cerros y las mejores tierras agrícolas, respectivamente, aunque con una clara diferencia con el primero, ya que es apreciable el papel de las inmobiliarias (legales e ilegales) en la expansión de la ciudad-región. En consecuencia, además de los innumerables impactos, como la pérdida de ecosistemas, flora y fauna, sitios de anidación y alimentación de especies endémicas y no endémicas, está la pérdida de la conectividad con otros ecosistemas: 10.200 hectáreas pertenecientes a humedales, suelos agrícolas y cerros se han transformado entre 1997-1998 y el año 2007-2008 en área construida para usos residencial, comercial, industrial, recreativo y de saneamiento.

Se identificaron también dos situaciones desfavorables respecto de la sustentabilidad de la ciudad-región durante el análisis de la variable Agua. Primera, el 99,9\% del agua requerida (consumo anual 2007-2008 fue de 977,8 millones de metros cúbicos) es "importada" desde otras zonas para la mayoría de los usos: ${ }^{7}$ consumo humano (potable urbana y rural), riego y embotellada; esto es, Bogotá tiene una dependencia absoluta de regiones aledañas para su abastecimiento de agua. La segunda situación adversa a la sustentabilidad consiste en que el $71,5 \%$ de las aguas residuales no son tratadas luego de que la Planta de Tratamiento de Aguas Residuales (PTAR) Salitre solo trató 126 millones de metros cúbicos en el año 2007-2008; por lo tanto, las externalidades negativas de las aguas contaminadas se "exportaron" hacia otras regiones fuera de los límites político-administrativos de la ciudad-región.

El consumo de agua para la minería en Bogotá fue la categoría de mayores dificultades para ser calculada, pues en $E l$ Acueducto (2003) y demás publicaciones de esta entidad, y otras relacionadas con el tema, no se encuentran explícitos tales reportes. 
Respecto de la variable Alimentos, se destacan dos procesos contrarios a los principios de la sustentabilidad, ocurridos en la ciudad-región durante el período 19971998 al 2007-2008. Primero, los suelos agrícolas de buena calidad disminuyeron y han sido sepultados por otras actividades que sustituyeron al sector agrícola. Esto se corroboró con el hecho de que la categoría de usos del suelo denominada urbana/industrial, cuyas hectáreas fueron incorporadas a la malla urbana de la ciudad-región, en esa década presentó la mayor variación creciente (37\%). Segundo, las actividades industriales de diversa índole, como rellenos sanitarios, extracción de áridos y deterioro de suelos por descargas contaminantes han disminuido aún más las posibilidades de que Bogotá genere la mayor parte de sus productos alimenticios y deba "importarlos" desde otras regiones. Las cifras así lo demuestran: del consumo total de alimentos (4.619.294 toneladas en el año 2007-2008), Bogotá importó desde otros territorios nacionales e internacionales aproximadamente el 99,96\%, y esta conclusión es confirmada por la Secretaría Distrital del Ambiente (SDA, 2007), al aseverar que la capital solo produce el $0,04 \%$ de alimentos para su consumo interno.

La ciudad-región de Bogotá reportó un consumo total de energía de 15.692 GWh (incluyendo energía eléctrica y gas natural), aproximadamente; no se incluyen en esta categoría los combustibles asociados a la variable transporte, para evitar la doble contabilidad en el método. La energía eléctrica fue obtenida de zonas externas a la jurisdicción de la capital; así, del consumo total de energía eléctrica (6.978 GWh), la ciudad-región importó el 100\% e igualmente importó el 100\% del gas natural (8.714 GWh). Solo produjo internamente el 100\% del consumo de energía renovable, cuyas cifras son imperceptibles, ya que corresponden a grandes sistemas de calentamiento de agua y calentadores solares domésticos para uso en centros de servicios comunitarios y urbanizaciones en Ciudad Tunal, Ciudad Salitre, Palacio de Nariño y la Empresa de Energía de Bogotá (EEB), demostrándose que las tecnologías más sustentables no son representativas a nivel de las alternativas energéticas utilizadas en Bogotá. En consecuencia, el consumo total de energía produjo 4.826.125 toneladas de $\mathrm{CO}_{2}$, que además de desmejorar el panorama de calidad del aire de la capital por las condiciones topográficas, bien puede decirse que no fueron absorbidas en la ciudad-región de Bogotá, sino que un alto porcentaje fue exportado hacia otras "regiones" vecinas, porque las emisiones de $\mathrm{CO}_{2}$ y los factores climáticos asociados no están restringidos por las fronteras.

Los materiales de construcción, minería metálica y no metálica, manufacturados, misceláneos, químicos y otros, pertenecen a la variable de menor profundización en la investigación, debido a los obstáculos enfrentados con relación a la disponibilidad de datos (confidencialidad de la empresa privada). El hecho es coincidente con el caso de la Región Metropolitana de Santiago (Chile). Únicamente se respalda con fuentes bibliográficas el consumo de 18.628.082 toneladas representadas en piedra, arena y grava; cementos, cales y yesos; otros materiales de construcción; productos metálicos; maquinaria y equipos; papel y cartón; y productos químicos. En consecuencia, se estima que los consumos de materiales son substancialmente más elevados que los obtenidos al final de la investigación, incluso mostrando 
cierto grado de incoherencia con la variable residuos. Queda claramente establecida la inexistencia de registros exclusivos de importaciones y exportaciones para esta variable en la ciudad-región de Bogotá y el carácter confidencial de los datos manejados por la empresa privada a cargo del sector industrial, convirtiéndose en obstáculos insalvables en el estudio y obviamente mermando la cuantificación de todas las categorías de materiales.

El actual estado de las actividades de registro, archivo y estadísticas para la ciudad-región de Bogotá coincide con los muchos diagnósticos realizados para Colombia; es decir, son evidentes los problemas de dispersión; la ausencia de orientaciones que propicien la integración y la articulación de la información (niveles de agregación, homogeneización y estandarización); las deficiencias en las estructuras de organización de las entidades, en la capacidad de planeación y en la coordinación interinstitucional; así como las limitaciones y rezago en los soportes tecnológicos, a excepción de las bases de datos propias de entidades privadas y del DANE.

En cuanto a Residuos, en 2007-2008 Bogotá generó 11.745 .970 metros cúbicos de escombros y cerca de 3,5 millones de toneladas de residuos: 2.902 .572 toneladas de residuos sólidos domiciliarios (RSD), 570.860 toneladas de residuos industriales y 7.320 toneladas de residuos hospitalarios; no se logró determinar el volumen correspondiente a los residuos de la minería (ladrilleras y chircales), por la inexistencia de datos oficiales al respecto. El reciclaje aún es incipiente (25\%) y solo 725.985 toneladas fueron recicladas para ese mismo período, aunque las disposiciones distritales y la sentida necesidad de los recicladores respecto de organizarse impactaron y siguen impactando de manera positiva y creciente en esta cultura sustentable. También el factor disposición final es importante en el análisis de la sustentabilidad, el que dio un resultado positivo para Bogotá y Santiago, ya que dentro de sus límites político-administrativos se tienen en funcionamiento las escombreras y los rellenos sanitarios para el depósito de los desechos procedentes de la ciudad (el vertedero Doña Juana, de Bogotá, atiende otros 65 municipios vecinos); en consecuencia, no hay exportación de externalidades negativas a causa de los residuos.

La variable Transporte muestra en ambas ciudades capitalinas un auge del transporte privado sobre el público y una tendencia al incremento del transporte aéreo, cuyos efectos directos en ambas situaciones es el aumento de las emisiones de $\mathrm{CO}_{2}$ y su impacto negativo en la valoración de la sustentabilidad de la ciudad-región y la región metropolitana. Tales afirmaciones están respaldadas para Bogotá en los siguientes hechos: en 1995, el 77\% de los residentes utilizaba el transporte público y el 19\% el transporte privado; sin embargo, en el año 2007 esta proporción se modificó: el $60 \%$ se movilizaba en transporte público, el $24 \%$ en transporte privado, y se reportan altos porcentajes para viajes en bicicleta y caminata. Durante este mismo año, los bogotanos realizaron al día cerca de 9,7 millones de viajes, de los cuales $17,3 \%$ fueron en modo no motorizado y el $82,6 \%$, en modo motorizado (Cámara Colombiana de Bogotá, 2009); como consecuencia de esta última situa- 
ción, durante el año 2007-2008 se recorrieron 45.374 millones de kilómetros en la ciudad-región, produciendo 5.081 .560 toneladas de $\mathrm{CO}_{2}$. El transporte privado fue responsable del $28 \%$ de las emisiones (1.413.530 toneladas en tan solo 7.027 millones $\mathrm{km} / \mathrm{pas}$ ) y el transporte público (incluyendo Transmilenio) fue responsable del $26 \%$ de las emisiones (1.329.014 toneladas, pero con 26.786 millones $\mathrm{km} /$ pas recorridos), una conclusión absolutamente de espaldarazo al transporte público. Los modos no motorizados de transporte, que no producen emisiones y reafirman la escala humana en la ciudad, alcanzaron 1.326 millones de kilómetros en bicicleta y 1.682 millones de kilómetros en caminata, pese a las peculiares condiciones topográficas de la ciudad-región para estas alternativas sustentables.

El cierre de la metodología se hizo mediante el cálculo de la Huella Ecológica Local de la ciudad-región de Bogotá para el año 2007-2008, donde el AFM se convirtió en la base de datos fundamental para la HEL (en el Cuadro 1 se muestran los resultados para ambas ciudades objeto de estudio). La HEL de Bogotá se estableció en 0,58 hectáreas locales per cápita (hlpc: huella ecológica expresada en hectáreas locales per cápita), a partir de factores de productividad/rendimiento locales. Dicha cifra significa que Bogotá requiere una superficie de 3.965.706 hectáreas para satisfacer las necesidades de consumos materiales y energéticas de sus habitantes, y también para la absorción de los desechos; es decir, al solo tener 173.674 hectáreas (véase Anexo 1, punto 7: Capacidad de carga) requiere un área 22,8 veces mayor a su territorio político-administrativo.

CUADRo 1 | Huella ecológica local (HEL) para la ciudad-región de Bogotá y la Región Metropolitana de Santiago

\begin{tabular}{|l|c|c|c|c|}
\hline \multirow{2}{*}{ Variable } & \multicolumn{2}{|c|}{ CIUDAD-REGIÓN DE BOGOTÁ } & \multicolumn{2}{|c|}{ REGIÓN METROPOLITANA DE SANTIAGO } \\
\cline { 2 - 5 } & $\begin{array}{c}\text { Área total } \\
\text { requerida }\end{array}$ & HEL per cápita & $\begin{array}{c}\text { Área total } \\
\text { requerida }\end{array}$ & HEL per cápita \\
\cline { 2 - 5 } & Ha & $\begin{array}{c}\text { Ha locales } \\
\text { per cápita }\end{array}$ & Ha & Ha locales per cápita \\
\hline Agua & 51.107 & 0,0075394 & 98.340 & 0,0162246 \\
\hline Alimentos & 2.504 .589 & 0,3694798 & 4.460 .608 & 0,7359300 \\
\hline Energía & 338.825 & 0,0499838 & 633.316 & 0,1044871 \\
\hline Materiales & 2.722 & 0,0004016 & 1.053 & 0,0001737 \\
\hline Residuos & 620 & 0,0000915 & 95 & 0,0000156 \\
\hline Transporte & 1.025 .521 & 0,1499275 & 2.118 .129 & 0,3500902 \\
\hline Construida & 42.322 & 0,0062434 & 457.868 & 0,0755409 \\
\hline Total HEL & 3.965 .706 & 0,5836670 & 7.769 .408 & 1,2824621 \\
\hline
\end{tabular}

FUENTE ELABORACIÓN PROPIA. 


\section{Discusión}

Las metodologías estandarizadas han sido requeridas por varios autores para que exista la posibilidad de establecer rankings internacionales. No obstante, se cataloga como más relevante la aplicación de métodos con utilidad en el nivel local, que nutren la comprensión de los stakeholders para la toma de decisiones que orienten la planificación de la ciudad (región) en el mediano y largo plazo, y que permiten obtener análisis de la sustentabilidad más cercanos al panorama del asentamiento evaluado, por encima de la comparabilidad a escala internacional. En el aporte de la investigación prevalece el mejoramiento del proceso de cálculo de los indicadores para hallar la sustentabilidad real de la urbe, antes que la estandarización de las metodologías en procura de comparaciones internacionales. Se convierte tal peculiaridad en un elemento fundamental y adicional de los indicadores de tercera generación: vinculantes, locales, sinérgicos y transversales, que incorporan simultáneamente variables con diversas categorías, atributos y dimensiones de la sustentabilidad urbana.

El cálculo del AFM se convierte en la base fundamental del cálculo de la HEL, considerando siete variables, cada una diferenciada en categorías y subcategorías (cercanas a setenta diversos atributos clave en la evaluación de la sustentabilidad). Incluso se incorporan algunos recursos bióticos y abióticos no establecidos en las metodologías originales, lo que permite dar un nivel equilibrado a gran parte de los flujos ocurridos en ambas ciudades, sin producir el efecto de que los flujos de grandes grupos dominan los flujos de sectores pequeños, descrito por Hinterberger, Giljum y Hammer (2003). Asimismo, en cuanto a los responsables de los impactos (Wiedmann, Minx, Barret \& Wackernagel, 2005; Yue et al., 2005), dicha discriminación de las variables para el análisis de los flujos permite visualizar los sectores con mayor o menor grado de responsabilidad; por ejemplo: en producción de emisiones de $\mathrm{CO}_{2}$ el transporte privado; los máximos consumidores de agua son la minería y riego para la RMS; y la preferencia en utilización de alternativas energéticas más limpias, como es el transporte no motorizado.

En consecuencia, el desglose de las variables ofrece a los tomadores de decisiones locales los datos y las tendencias clave que podrán respaldar las iniciativas del sector público en pro de adoptar estrategias sustentables que involucren a la sociedad civil y la empresa privada. Las principales tácticas holísticas identificadas se relacionan con la disminución de los 14 millones de toneladas de $\mathrm{CO}_{2}$ producidas anualmente por el transporte y los consumos energéticos en cada una de las ciudades latinas objeto de estudio; el fomento del $100 \%$ a las actividades agrícolas dentro de la región y la protección de los suelos agrícolas de alta calidad; la eficiencia en el riego para aumentar el actual $40 \%$ para la producción local de los alimentos; el impulso con mayor ahínco a la cultura del reciclaje de manera de

hacer crecer ese $8 \%$ y $25 \%$ de la RMS y Bogotá, respectivamente, lo que permite la disminución de suelo destinado a rellenos sanitarios y también el resguardo 
del suelo agrícola; y aumentar la demanda de la escala humana en la ciudad para favorecer otros medios limpios en la locomoción.

El enfoque conmensuralista tanto del AFM como de la HEL favorece el acercamiento a la transversalidad y cada vez más el alejamiento del análisis sectorial. Asimismo, el enfoque apoyado en las tendencias ocurridas en los territorios donde se asientan y se sustentan las ciudades para dos períodos, uno en la década de los 1990 y otro para la década de los años 2000, provoca un acierto coherente con el proceso de cuantificación de la sustentabilidad, al determinar las tendencias cuantitativas de las variables en esos diez años, y se compensa el comportamiento estático en un punto del tiempo reportado por IWM (2002) y Yue et al. (2005).

Al concluir los dos ejercicios para la Región Metropolitana de Santiago (Chile) y la ciudad-región de Bogotá (Colombia), se demuestra la complementariedad existente entre el AFM y la HEL y el alto grado de aporte, cercano al $80 \%$, en la cuantificación de la sustentabilidad respecto de otros indicadores, obviamente con la incorporación de las dimensiones espacio-temporal y todas las demás innovaciones que en este artículo se sintetizan. En consecuencia, las medidas correctivas estipuladas e implementadas mediante las políticas públicas podrán ser más específicas, más detalladas, al quedar mejor identificadas las relaciones y funciones de los sociosistemas capitalinos con los ecosistemas que los sustentan. Igualmente, esta dupla de indicadores se reconoce como una herramienta pedagógica de utilidad para describir la demanda humana sobre la naturaleza, coincidiendo con Wiedmann et al. (2005), Yue et al. (2005), Muñiz y Galindo (2005), IWM (2002) y Jenerette et al. (2005), quienes solo advertían de tal cualidad para la huella ecológica.

Los cálculos incorporan casi la totalidad de los flujos de entrada y salida en la ciudad al incluir las series de producción, exportación, importación y consumo para todas y cada una de las variables, pero no incluyen las pérdidas ocurridas en los procesos de producción, como tampoco los flujos indirectos asociados a importaciones y exportaciones; estos últimos ofrecen las mayores dificultades de cálculo y ameritan la incorporación de metodologías más especializadas, como Life Cycle, mochila ecológica, MIPS (Material Input Per Unit of Service/Insumo Material Por Unidad de Servicio), MIOT (Monetary Input-Output Table/ Matriz de Insumo-Producto Monetario) y PIOT (Physical Input-Output Tablel Matriz de Insumo-Producto Físico), pues no solamente se trata de establecer la cantidad de toneladas exportadas o importadas, sino también de considerar en las estimaciones las toneladas de materiales necesarios para la elaboración de dichos productos, como lo afirman Hinterberger, Giljum y Hammer (2003), Giljum (2004), y Muñoz y Roca (2006).

Un componente esencial del desarrollo de la investigación fue el dilucidar las críticas referentes al análisis de flujo de materiales y la huella ecológica; no obstante, el auténtico desafío en ambos estudios fue dar un paso más adelante y superar algunas de estas críticas en forma proactiva, para potencializar el uso del 
AFM y la HEL cada vez con mayores grados de seguridad, eficiencia y efectividad, basados en los avances del conocimiento en cuanto a las intrincadas metodologías de cálculo. Es así como a continuación se abordan tales discusiones y las propuestas de medidas correctivas.

En la aplicación de la huella ecológica, Muñiz y Galindo (2005) reconocen las dificultades para otorgarle un peso fundamental a la tecnología y asignarle a una misma superficie diversos recursos; este último aspecto se rebate al tener igualdad de condiciones en el indicador, pues a una misma superficie donde se asienta la urbe también se le asignan diversas externalidades negativas, y son cuantificadas en la huella. En esta misma línea, se hallaron algunos conflictos para correlacionar los usos del suelo de Santiago y Bogotá con las seis categorías de suelos propuestos por Wackernagel y Rees (2001), debido a que se consideran muy limitadas; para superar tal restricción y lograr el encuadre, se realizó un proceso de asociación lógica; un ejemplo representativo fue asociar la categoría "área construida" con tres usos presentes en dichos territorios urbanos: zonas urbanizadas, áreas industriales y terrenos desprovistos de vegetación, porque cumplen con el requisito de los autores de la huella, es decir, ser zonas biológicamente improductivas.

En la simplificación de los procesos naturales se encuentran serias debilidades de los indicadores de tercera generación para la sustentabilidad, que por naturaleza son diversos y complejos en sus funciones y relaciones. La simplificación facilita la comprensión de la complejidad del metabolismo urbano, pero acarrea la reducción de los patrones naturales a solo números, lo que permite el cómputo para la asignación de áreas, pero no refleja directamente los impactos. En este sentido y expresado de forma más clara, se refiere a las explotaciones mineras, la disposición de residuos y el abastecimiento de agua, que corresponden a los tres principales patrones naturales que incorporan dinámicas complejas en su evaluación. Los dos primeros patrones naturales mencionados -explotaciones mineras y disposiciones de residuos- en la práctica exigen acciones de valoración tridimensional, lo que se aplica incluso a los reservorios de agua. Esto lleva a conversiones ininteligibles, cuando se pasa de unidades de volumen a unidades de superficie, como las usadas en el método de cálculo de la huella, con su escala bidimensional. La profundidad de las excavaciones mineras, el fondo de las celdas de disposición de residuos, el agua subterránea y su conexión directa con los fenómenos superficiales, requieren un manejo diferente, que considere su tridimensionalidad.

Se rebate que el principal obstáculo que debe superar el investigador durante la aplicación del AFM y la HEL es la disponibilidad de datos a escala región metropolitana/ciudad-región; hoy puede afirmarse que un altísimo porcentaje de la información requerida existe en forma dispersa, pero con dedicación es posible hallarla; o se puede calcular mediante numerosos procedimientos matemáticos, estadísticos y de lógica. Por lo tanto, aunque la presentación de las series de datos esté agrupada en algunos casos, o en forma desagregada en otros (por comuna/localidad), o registrada en unidades que merecen procesos 
de conversión, o requiriendo hacer visibles las series casi invisibles por el modelo de almacenamiento de los datos, o estableciendo la veracidad de los datos según el origen/fuente, es viable la superación del desafío asociado a la disponibilidad de información.

La cúspide de la recolección de datos para proceder al cálculo de los indicadores se ubica en la homogeneización de series de datos en dos unidades, de la siguiente forma: toneladas para el AFM y hectáreas locales para la HEL; en este procedimiento, la extrapolación y la doble contabilidad se convierten en dos principios primordiales durante la realización de los innumerables cálculos. La extrapolación es una alternativa matemática de utilidad reconocida y en ocasiones su uso es ineludible; sin embargo, su aplicación indiscriminada en variables de peso en estos dos métodos, sin concienzudas búsquedas de cifras a la escala seleccionada, puede acarrear drásticos errores en los cálculos. Tal situación pudo ser corroborada, entre otros casos, con la variable Energía, para la cual afortunadamente se obtuvo el balance regional a partir de bases estatales, lo que evitó incurrir en extrapolaciones desde la escala nacional, lo que habría provocado una estimación cinco veces mayor que la real en cuanto al consumo total de energía, específicamente para la Región Metropolitana de Santiago. En síntesis, la cercanía de los niveles regional y local otorga un menor margen de error respecto de la relación nacional-local.

Evitar la doble contabilidad exige una especial atención, lo que se logra mediante análisis permanentes y exhaustivos de todas y cada una de las variables y sus categorías, razonamientos lógicos durante la desagregación de las actividades y reflexiones de transversalidad para detectar la repetición de subcategorías, pues hacer caso omiso de tal principio indudablemente lleva a errores, y los cálculos del análisis de flujo de materiales y la huella ecológica local quedarán substancialmente sobreestimados.

El cálculo tradicional de la huella ecológica mediante factores de productivi$\mathrm{dad} /$ rendimiento globales es, según Muñiz y Galindo (2005), uno de los aspectos que mayor debilidad le generan al indicador, debido a las erróneas conclusiones a que puede llevar el uso de dichos factores. Tal premisa se comprobó con el ejercicio de cálculo de la huella ecológica de la Región Metropolitana de Santiago para el año 2002 (Cuadro 1), la que se estimó en 1,28 hectáreas locales per cápita; y con factores globales, en 3,6 hectáreas globales per cápita. ${ }^{8}$ La diferencia es evidente; una proporción tres veces mayor, que significa un radical incremento del valor agregado de la huella. Idéntica situación se observó en el caso del Área Metropolitana de Santiago para el año 2002: se calculó en 1,15 hectáreas locales per cápita con factores locales y 3,24 hectáreas locales per cápita con factores globales (León, 2006). De nuevo casi tres veces mayor el cálculo a partir de factores globales respecto de los factores de rendimiento local.

8 Se aclara que se utilizaron factores locales o "autóctonos", excepto en dos variables muy especiales: la energía, donde se aprobaron los factores globales; y los alimentos provenientes del mar, debido a las dificultades para definir el factor local de rendimiento de los mares. 
Tal disparidad de resultados en el caso de Santiago de Chile respalda la propuesta del indicador denominado Huella Ecológica Local (HEL) (adición del adjetivo "local"), cuya valoración se realiza basado en factores de productividad o rendimiento locales y, en consecuencia, la dupla se modifica a AFM y HEL, la que fue implementada para el caso de la ciudad-región de Bogotá.

Este concepto transformador -huella ecológica local- es uno de los aportes e innovación después de llevada a cabo la investigación. Se insiste en que al utilizar factores de rendimiento locales, prevalece el mejoramiento de los indicadores para optimizar la cuantificación de la sustentabilidad de una urbe específica, antes que la estandarización de los métodos o metodologías en procura de las comparaciones o rankings internacionales.

Finalmente, se sugiere como factible estrategia administrativa que la dupla AFM y HEL sea incorporada dentro de la institucionalidad y las políticas públicas, de modo que la continuidad del cálculo con sus actualizaciones queden a cargo del Instituto Nacional de Estadísticas (INE) y el Departamento Administrativo Nacional de Estadísticas (DANE) en la Región Metropolitana de Santiago y la ciudad-región de Bogotá, respectivamente. De esta forma pueden enriquecerse día a día las bases de datos utilizadas, retroalimentarlas con otras bases oficiales y privadas, minimizando las divergencias de cifras entre fuentes bibliográficas, todo en pro de orientar las decisiones de planificación en el mediano y largo plazo hacia una mayor sustentabilidad de las ciudades. $\odot$ EURE

\section{Agradecimientos}

La presente investigación se realizó durante los años 2009 y 2010 con el apoyo de la Dirección de Investigaciones (antes INIP), el Grupo de Investigación "Ecología Urbana" de la Facultad de Ciencias Ambientales de la Universidad Piloto de Colombia, y los estudiantes profesionales de las Cohortes 2008 y 2009 de la Especialización en Gestión Ambiental Urbana.

Es pertinente reconocer la efectiva colaboración de algunos funcionarios públicos en la ubicación más acertada de las bases de datos y la facilitación de documentos compiladores por parte de la empresa privada, siempre y cuando no se tratara de información de carácter "confidencial", es decir, aquella con sensibilidad comercial y de mercado, que la competencia no pudiese conocer. Además, se agradece el apoyo de los siguientes colegas externos a la Universidad Piloto: Ing. Jhon Jairo Posada, de la Universidad Nacional de Colombia; y Arq. Marko Quiroga, Doctorando de la Pontificia Universidad Católica de Chile. 


\section{Referencias bibliográficas}

Agudelo, L. C. (2002). Indicadores de sostenibilidad y ordenación del territorio. Huella ecológica y ecosistemas estratégicos en Medellín, Colombia. En Ordenación del territorio, política regional, medio ambiente y urbanismo (pp. 841-845). Recoge los contenidos presentados al III Congreso Internacional de Ordenación del Territorio: Guijón (Asturias), 3 a 6 de julio de 2002. Madrid: Asociación Interprofesional de Ordenación del Territorio, Fundicot. Disponible en http://bit.ly/10O9VXu

Barton, J., Jordán, R., León, S. \& Solís, O. (2007). ¿Cuán sustentable es la Región Metropolitana de Santiago? Metodologias de Evaluación de la Sustentabilidad. Santiago: Comisión Económica para América Latina y el Caribe (Cepal), Colección Documentos de proyectos, LC/W.170. Disponible en http://www.eclac.cl/publicaciones/xml/8/32978/LCW-170.pdf

Cámara de Comercio de Bogotá (CCB). (2009). Link: http://www.ccb.org.co/portal/default.aspx

Corporación Autónoma Regional de Cundinamarca (2000). Bogotáy Cundinamarca, expansión urbana y sostenibilidad. Bogotá: Autor.

Castro, M. (2002). Indicadores de Desarrollo Sostenible Urbano. Capítulo 3 de Indicadores de Desarrollo Sostenible Urbano: una aplicación para Andalucía (pp. 121-166). Sevilla: Instituto de Estadística de Andalucía. Permiso a Tesis Doctorales, 2004. Disponible en http://www. eumed.net/tesis/jmc/cap03.pdf. Edición electrónica gratuita (2009). Texto completo en www.eumed.net/tesis/jmc/

Departamento Administrativo Nacional de Estadísticas (DANE), Colombia. Link: www. dane.gov. co/daneweb_V09/ Revisada de abril 2009 a septiembre de 2010.

Ducci, M. E. (1998). La dimensión política de la sustentabilidad urbana. Santiago: Instituto de Estudios Urbanos y Territoriales (IEU+T), Pontificia Universidad Católica de Chile, Serie Azul, 10 .

Giljum, S. (2004). Trade, material flows and economic development in the South: The example of Chile. Journal of Industrial Ecology, 8(1-2), 241-261. doi: 10.1162/1088198041269418

Gross, P. \& Arrué, R. (2005). Indicadores de sustentabilidad a nivel local. En Gestión ambiental a nivel local (pp. 276-290). Santiago: Ediciones Surambiente.

Hinterberger, F., Giljum, S. \& Hammer, M. (2003). Material Flow Accounting and Analysis (MFA): A valuable tool for analyses of society-nature interrelationships. Viena: Sustainable Europe Research Institute (SERI). Disponible en http://bit.ly/1aOOBFN

Chartered Institution of Wastes Management/Environmental Body (IWM/EB). (2002). City Limits. A resource flow and ecological footprint analysis of Greater London. Londres: Best Foot Forward Ltd. Disponible en http://www.citylimitslondon.com/downloads/Complete\%20 report.pdf

Franchini, T. \& Dal, A. (2000). Indicadores urbanos y sostenibilidad. Hacia la definición de un umbral de consumo sostenible de suelo. Ciudady Territorio. Estudios Territoriales, 32(123), 41-55.

Jenerette, D., Wu, W., Goldsmith, S., Marussich W., A. \& Roach, W. J. (2005). Contrasting water footprints of cities in China and the United States. Ecological Economics, 57(3), 346-358. http://dx.doi.org/10.1016/j.ecolecon.2005.04.016

Larrea, D., Martínez, V. I., Quiroga, M. \& Román, A. (2007). Indicadores de sustentabilidad para Santiago de Chile. Santiago. (s/d). 
León, S. (2006). ¿Tiene sustentabilidad la Región Metropolitana de Santiago? Análisis de Flujo de Materiales y Huella Ecológica. Tesis de Maestría. Pontificia Universidad Católica de Chile, Santiago.

León, S. (2009). Sustentabilidad de Bogotá. Documento de trabajo. Bogotá: Universidad Piloto de Colombia.

Muñiz, I. \& Galindo, A. (2005). Urban form and the ecological footprint of commuting. The case of Barcelona. Ecological Economics, 55(4), 499-514. http://dx.doi.org/10.1016/j.ecolecon.2004.12.008

Muñoz, J. P. \& Roca, J. (2006). Las bases materiales del sector exportador chileno: un análisis inputoutput. Revista de la red iberoamericana de economía ecológica, 4, 27-40. Disponible en http://www.redibec.org/IVO/rev4_03.pdf

Norgaard, R. (1984). El potencial del desarrollo coevolucionista. Publicado con el título Coevolutionary Development Potential, en Land Economics, 60(2), 160-173, mayo de 1984, y traducido por M. I. Núñez y F. Aguilera para usos docentes (Universidad de La Laguna, Tenerife, España).

Quiroga, R. (2001). Indicadores de sostenibilidad ambiental y de desarrollo sostenible: estado del arte y perspectivas. Santiago: Comisión Económica para América Latina y el Caribe (Cepal), División de Medio Ambiente y Asentamientos Humanos. Serie Manuales, 16, LC/L.1607-P.

Secretaría Distrital de Ambiente (SDA), Colombia (2007). Atlas Ambiental de Bogotá D.C. Bogotá: Autor.

Turner, K. (1992). Speculations on weak and strong sustainability. CSERGE (Centre for Social and Economic Research on the Global Environment, University of East Anglia), Working Paper Gec 92-26. Disponible en http://cserge.ac.uk/sites/default/files/gec_1992_26.pdf

Wiedmann, T., Minx, J., Barret, J. \& Wackernagel, M. (2005). Allocating ecological footprints to final consumption categories with input-output analysis. Ecological Economics, 56(1), 28-48. http://dx.doi.org/10.1016/j.ecolecon.2005.05.012

Wackernagel, M. \& Rees, W. (2001). Nuestra huella ecológica. Reduciendo el impacto humano sobre la tierra. Santiago: Instituto de Ecología Política (IEP)/LOM Ediciones.

Yue, D., Xu, X., Li, Z., Hui, C., Li, W., Yang, H. \& Ge, J. (2005). Spatiotemporal analysis of ecological footprint and biological capacity of Gansu, China 1991-2015: Down from the environmental cliff. Ecological Economics, 58(2), 393-406. http://dx.doi.org/10.1016/j. ecolecon.2005.07.029 


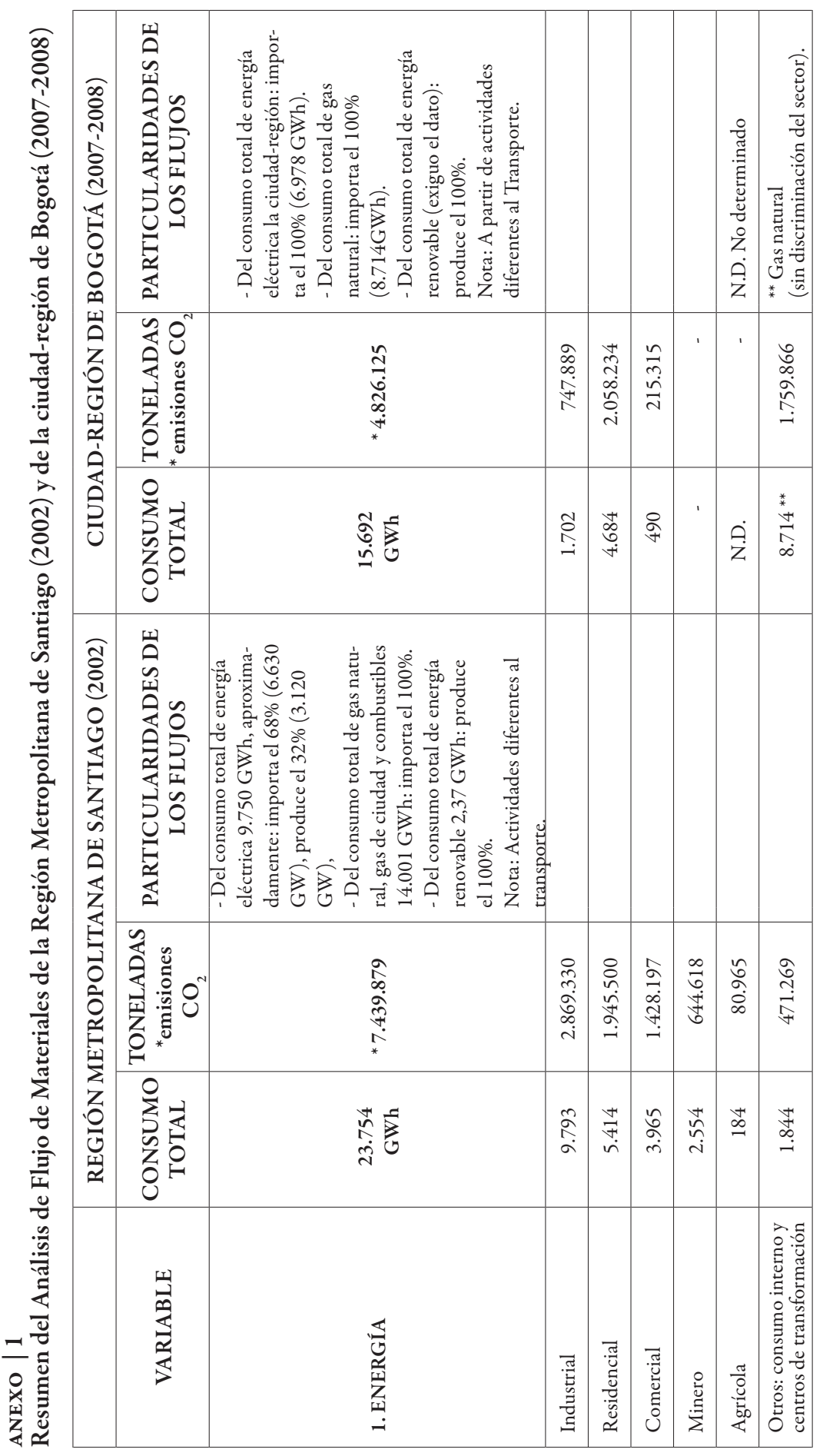




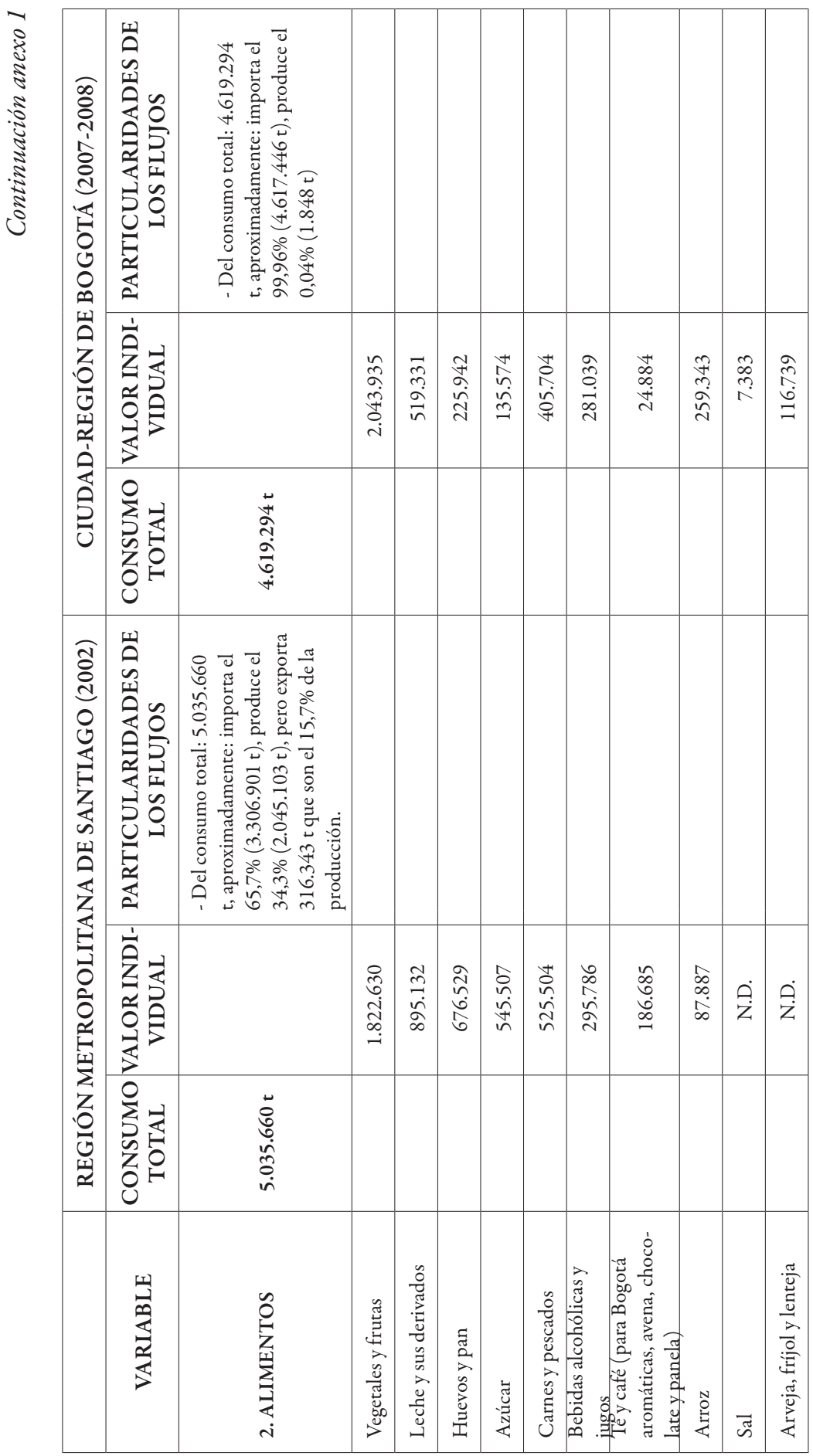




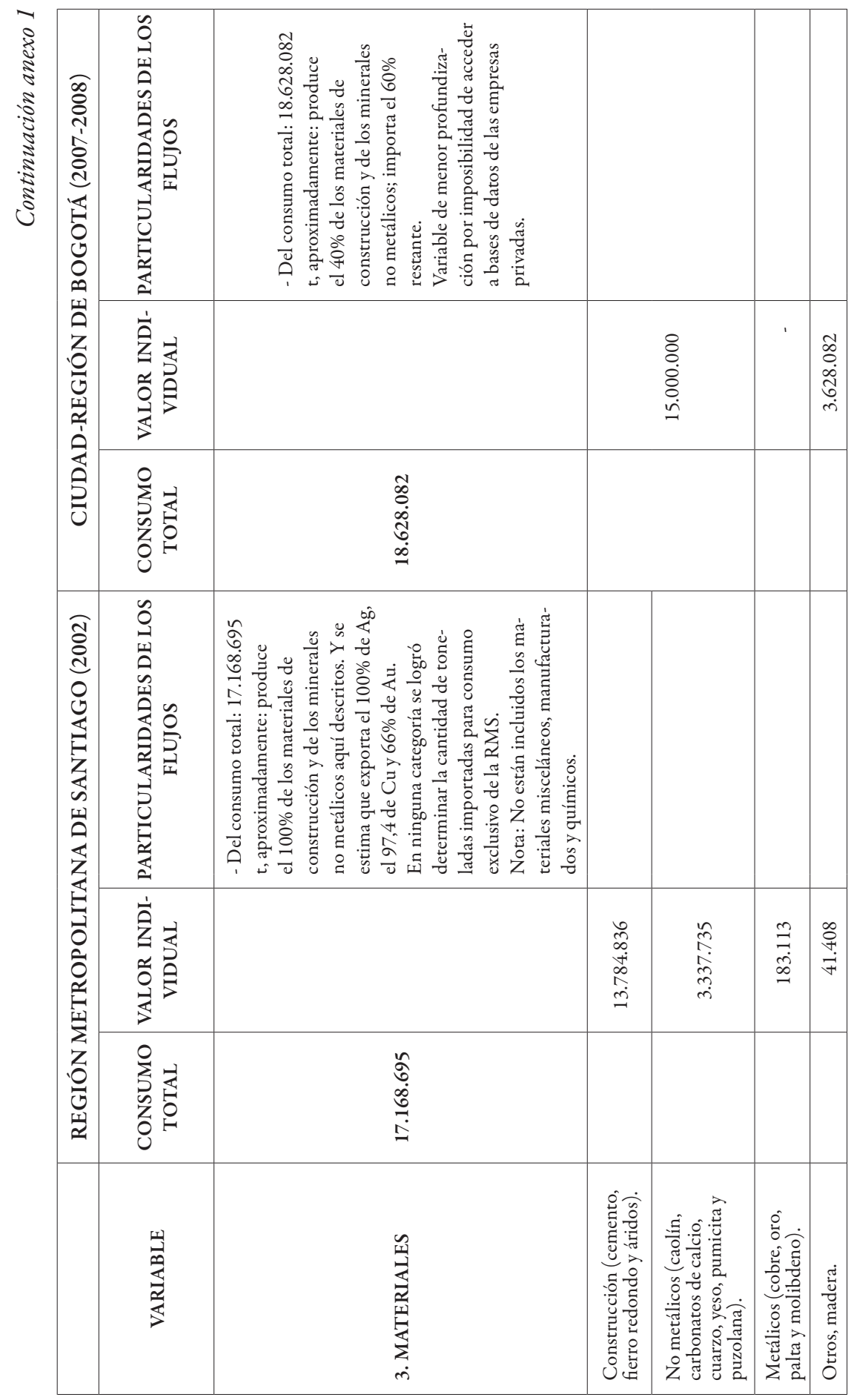


León | Indicadores de tercera generación para cuantificar la sustentabilidad urbana... | CEURE

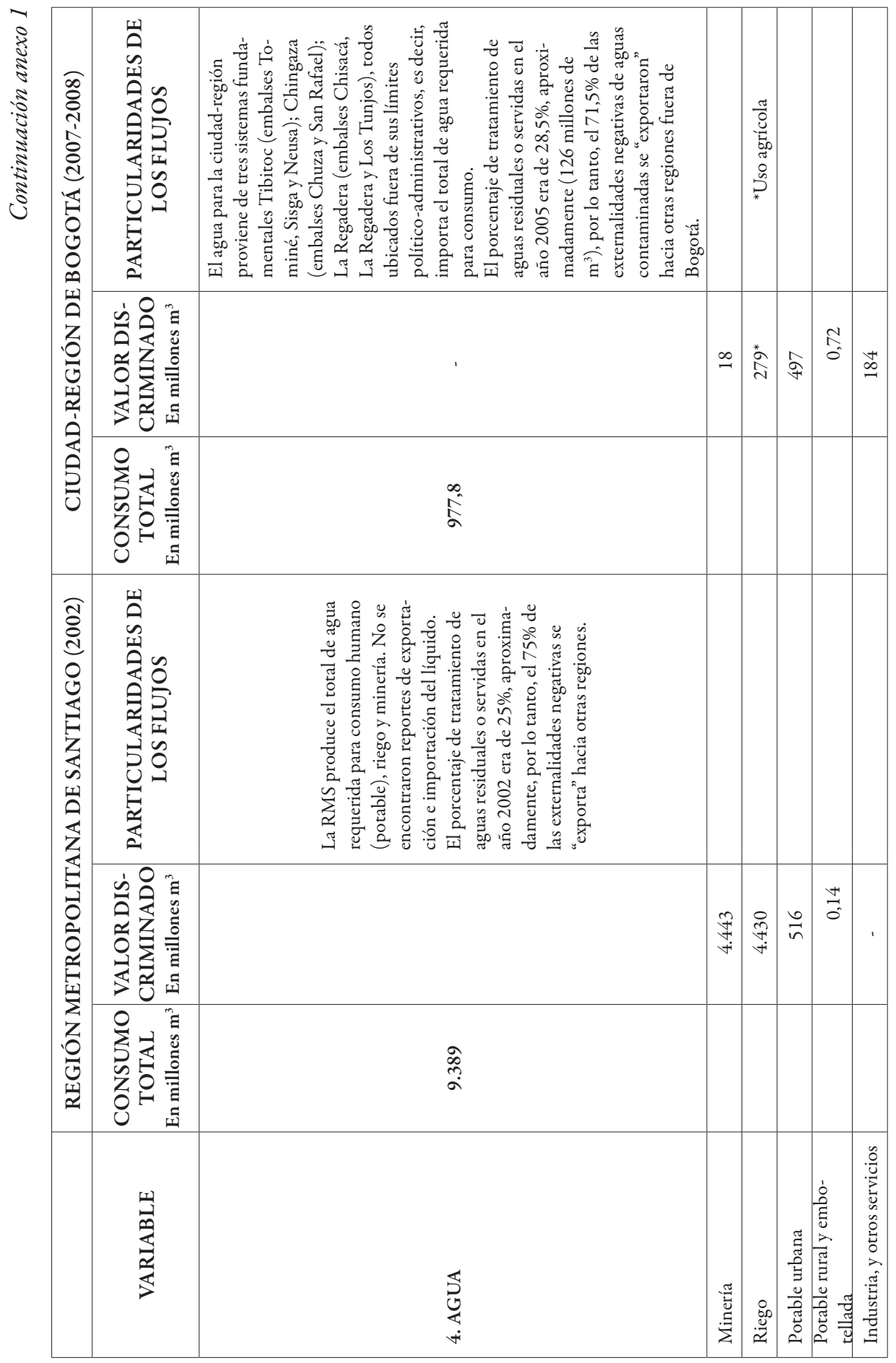




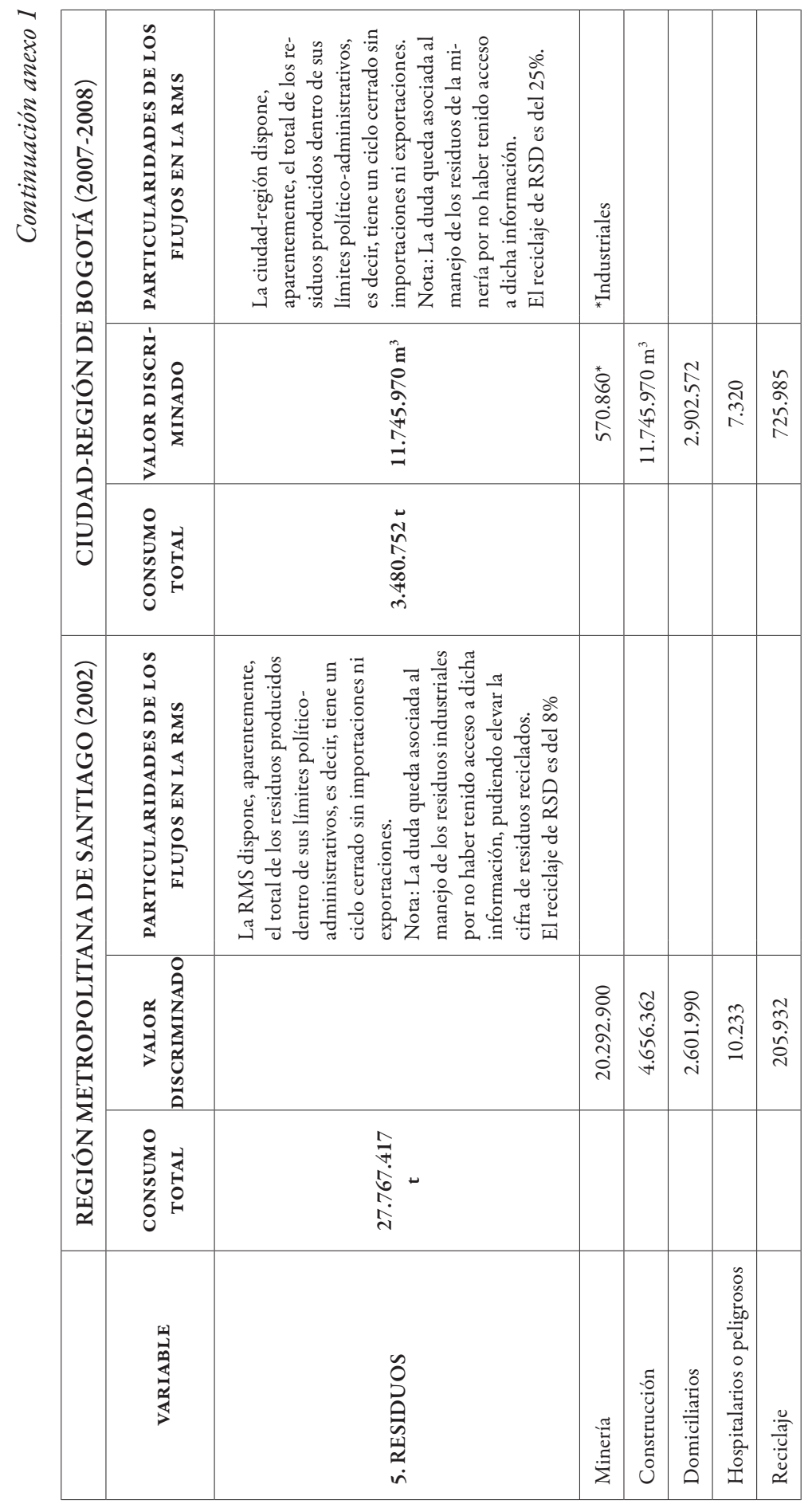




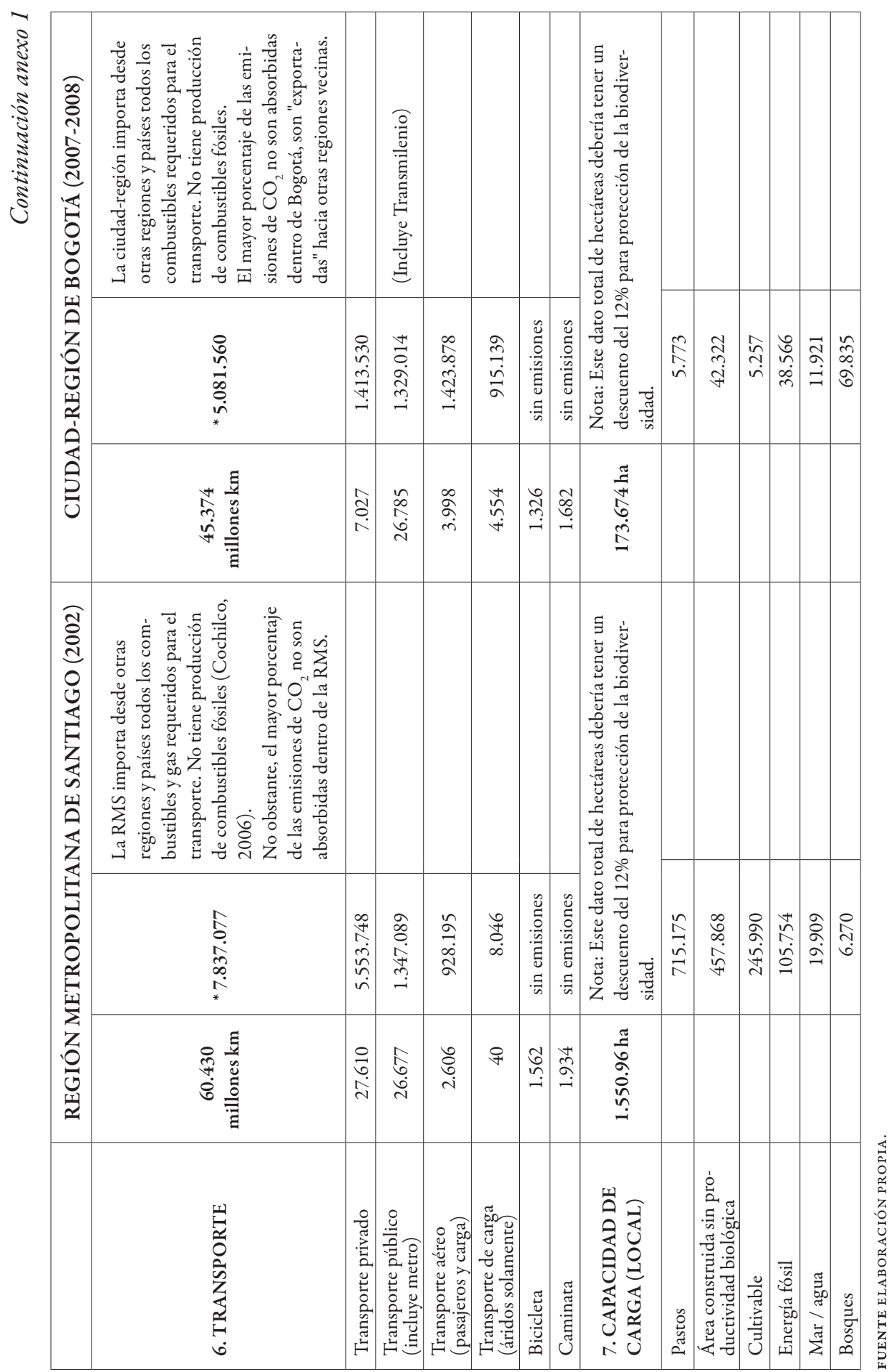

